\title{
Review
}

\section{Overview of recent progress in fisheries acoustics made by Ifremer with examples from the Bay of Biscay}

\author{
Verena M. Trenkel ${ }^{1, a}$, Laurent Berger ${ }^{2}$, Sébastien Bourguignon ${ }^{3}$, Mathieu Doray ${ }^{1}$, Ronan Fablet ${ }^{4,6}$, \\ Jacques Massé $^{1}$, Valérie Mazauric ${ }^{5}$, Cyrille Poncelet ${ }^{2}$, Gael Quemener ${ }^{2}$, Carla Scalabrin ${ }^{3}$ \\ and Hector Villalobos ${ }^{1,7}$ \\ 1 Ifremer, Département EMH, rue de l'île d'Yeu, BP 21105, 44311 Nantes Cedex 3, France \\ 2 Ifremer, Département NSE, BP 70, 29280 Plouzané, France \\ 3 Ifremer, Laboratoire LTH, BP 70, 29280 Plouzané, France \\ ${ }^{4}$ Institut Telecom/Telecom Bretagne, CNRS UMR 3192, Lab-STICC, CS 83818, 29238 Brest Cedex 3, France \\ ${ }^{5}$ Ifremer, Département Direction des moyens et opérations navals, 155 rue Jean-Jacques Rousseau, 92138 Issy-les-Moulineaux, France \\ ${ }^{6}$ Université européenne de Bretagne, 5 Bd René Laennec, 35000 Rennes, France \\ 7 Current address: CICIMAR-IPN, Av. Instituto Politécnico Nacional s/n., Col. Playa Palo de Sta. Rita, La Paz, BCS 23090, Mexico
}

Received 18 November 2008; Accepted 9 June 2009

\begin{abstract}
This paper provides an overview of the progress Ifremer has made recently in fisheries acoustics and the study of small pelagic fish by: i) pushing observation frontiers using a range of platforms including an autonomous underwater vehicle, AUV, ii) developing measuring instruments and methods and iii) studying fish distributions. Presently, information from several frequencies of single-beam echosounders is routinely collected together with data from the ME70 multibeam echosounder. For onboard data acquisition control the HERMES software was developed. The new MOVIES 3D software includes modules for simultaneous realistic 3D visualisation and post-processing such as bottom detection, school extraction and calculation of descriptors and integration of all acoustic data. Several data analysis methods are being developed and some initial results are presented. Finally, results on the spatial distribution of small pelagic fish schools in the Bay of Biscay illustrate the role that acoustics can play, and are already playing, in the implementation of an ecosystem approach to fisheries.
\end{abstract}

Key words: Multibeam echosounder / Oceanographic AUV / Pelagic fish / Fisheries acoustics

\begin{abstract}
Résumé - Cet article présente une vue d'ensemble des avancées récentes de l'Ifremer en acoustique halieutique et une étude des petits poissons pélagiques tenant compte : i) de l'extension des limites de l'observation, en utilisant une gamme diverse de plates-formes dont un engin sous-marin autonome (AUV), ii) des développements méthodologiques et d'instruments de mesures, iii) de l'étude de la répartition des poissons. Désormais, les données de plusieurs fréquences des sondeurs mono-faisceaux sont collectées en routine en parallèle à celles du sondeur multifaisceau ME70. Le logiciel HERMES a été développé pour le contrôle de l'acquisition des données à bord. Le nouveau logiciel MOVIES 3D comprend des modules de visualisation réaliste en 3D et de post-traitement (dont la détection du fond, l'extraction de bancs et le calcul de leurs descripteurs ainsi que l'intégration de toutes les données acoustiques). Plusieurs méthodes d'analyse de données sont en cours de développement et quelques premiers résultats sont présentés. Enfin, les résultats relatifs à la répartition spatiale des bancs de petits poissons pélagiques dans le golfe de Gascogne illustrent le rôle actuel et potentiel de l'acoustique dans la mise en place d'une approche écosystémique des pêches.
\end{abstract}

\section{Introduction}

Acoustic methods are the standard methods for obtaining abundance indices for pelagic and some demersal fish

\footnotetext{
a Corresponding author: verena.trenkel@ifremer. fr
}

species (Simmonds and MacLennan 2005). Increasingly they are also playing a role for ecosystem monitoring (e.g. Massé and Gerlotto 2003; Koslow 2009). Their use has a long history at Ifremer and its predecessor institute, CNEXO. Since the late 1970s, acoustic surveys have been carried out on the French shelf of the Bay of Biscay. They were originally undertaken 
sporadically and with limited coverage (Diner and Le Men 1983). Since 2000 they have been conducted annually, covering the whole French part of the shelf. At the same time, research into the properties of acoustic fish measurements has been carried out using simulation-based and empirical approaches. This has led, for example, to the development of a now widely used algorithm for correcting school length measurements which are biased by the increase of beam pattern with depth (Diner 1999, 2001). Another example is MOVIES, one of the early software developments for estimation of biomass by acoustics and fish shoal extraction and characterisation (Weill et al. 1993). MOVIES has allowed, among others, to test and compare different methods of biomass estimation (Massé and Rouxel 1991), to estimate the variance of biomass estimates due to species identification (Petitgas et al. 2003), to describe the spatial structure of fish schools (Scalabrin and Massé 1993; Massé 1996) and of aggregations around fish aggregation devices (Doray et al. 2007; Moreno et al. 2007), their diel variations (Zwolinski et al. 2007) and the characteristics of clusters of schools (Petitgas et al. 2001). Since 1997, the $\mathrm{R} / \mathrm{V}$ Thalassa, a modern, noise-reduced fisheries research vessel, has become an important operating platform for acoustic research, particularly since 2002 , when it was equipped with five single-beam Simrad ER60 echosounders (18, 38, 70, 120 and $200 \mathrm{kHz}$ ).

More recently, together with the manufacturer Simrad, Ifremer has developed a fully calibrated fisheries research multibeam echosounder, the ME70, which is installed on R/V Thalassa. See Trenkel et al. (2008) for a description of the system and its potential contribution to fisheries research. Simultaneously, a sonar version, the MS70, was developed by Simrad and the Norwegian Institute for Marine Research (IMR). The ME70 offers many new opportunities for ecological studies but presents also technical challenges in terms of data management and analysis. Recent advances in meeting these challenges are described in this paper, together with some new insights into pelagic fish community structure. In terms of other survey platforms, the autonomous underwater vehicles (AUV) developed by Ifremer are expected to extend the areas that can be surveyed acoustically (Opderbecke and Laframboise 2007; Rigaud 2007). Recent experiences with using the AUV as a platform for biomass estimation by acoustics are reported here.

In the following, recent progress made by Ifremer in fisheries acoustics is presented in the areas of observation platforms, acoustic data analysis and the study of small pelagic fishes in the Bay of Biscay (Northeastern Atlantic), illustrating the use and potential contribution of acoustic methods for the implementation of the ecosystem approach to fisheries (EAF).

\section{Extending observation frontiers}

The operating platform on which an echosounder is installed is a principal factor controlling the observation volume. Surveys covering large areas on the continental shelf commonly use hull-mounted vertical echosounders with an effective observation volume ranging from about $10 \mathrm{~m}$ below the sea surface to less than one meter above the sea floor, depending on echosounder configuration and bottom depth. Other operating platforms are required for surveillance outside this volume. Single-beam echosounders provide two-dimensional views (vertical and along-ship track dimensions), while multibeam systems add the third dimension (across-ship track).

\subsection{AUV for acoustic observations near the sea floor and below the sea surface}

Several physical factors influence the suitability of hullmounted acoustic methods for fish biomass estimation. Beam width in combination with depth, but also pulse duration and bottom topography, determine the extent of the dead zone near the sea floor for which no information is available (Ona and Mitson 1996). Another layer that cannot be sampled is situated near the sea surface. It can extend to around $15 \mathrm{~m}$ below the surface, depending on the acoustic frequency, vessel draft or depth of the drop keel and sea state. This upper layer is called the "surface blind zone" (Scalabrin et al. 2009; Totland et al. 2009).

There are at least two ways to reduce the volume of the dead zone in order to improve acoustic sampling of fish close to the seabed: i) lowering the transducer to the bottom using a towed body (Kloser 1996; Dalen et al. 2003) or an AUV (Fernandes et al. 2003); ii) reducing the transducer beam width, which has the drawback of decreasing the acoustically observed volume (Fig. 1). One advantage of using AUV compared to towed bodies is their low noise level (Fernandes et al. 2000). Numerous studies have shown that fish can react to an approaching survey vessel with different avoidance behaviours (Soria et al. 2003; Gerlotto et al. 2004; Handegard and Tjøstheim 2005); close-up reaction of herring towards an AUV has also been observed (Patel et al. 2004). However, differences in reaction to different vessels are not explainable only by noise levels (Ona et al. 2007; De Robertis et al. 2008); hence, noise reduction might not be the only factor to be considered when selecting the observation platform. Towed bodies operated from a vessel might provide data as good as those from an AUV, but their deployment is not without problems. The main limitations of AUVs are that they operate at slower speeds than vessels and certain fast moving fish schools, might have to be escorted by a vessel for security reasons and their deployment and recovery can be logistically demanding if they are heavy and the sea is rough.

For observing individuals in the surface blind zone there are at least three possibilities: i) towed bodies and AUVs, but this time using an upwards looking transducer (Fernandes et al. 2000); ii) quantitative multibeam sonars such as the MS70 and iii) moored inverted echo sounders (albeit only for small study areas (Trevorrow 2005). The choice of method will clearly depend on the size of the survey area and the observation duration. Continuous observations are only feasible with moorings (Fabi and Sala 2002; Axenrot et al. 2004; Scalabrin et al. 2005). The same considerations regarding noise levels apply to the choice between vessels or separate platforms.

Since 2004 Ifremer owns two identical medium-sized AUVs (Aster ${ }^{X}$ and $I d e f^{X}$ ) which can be used as platforms for fisheries acoustics (Table 1). They are fitted with two acoustic transducers operating at 70 and $200 \mathrm{kHz}$. Depending on the objectives of the study, the transducers can be both positioned either looking upwards or downwards or in opposite directions 


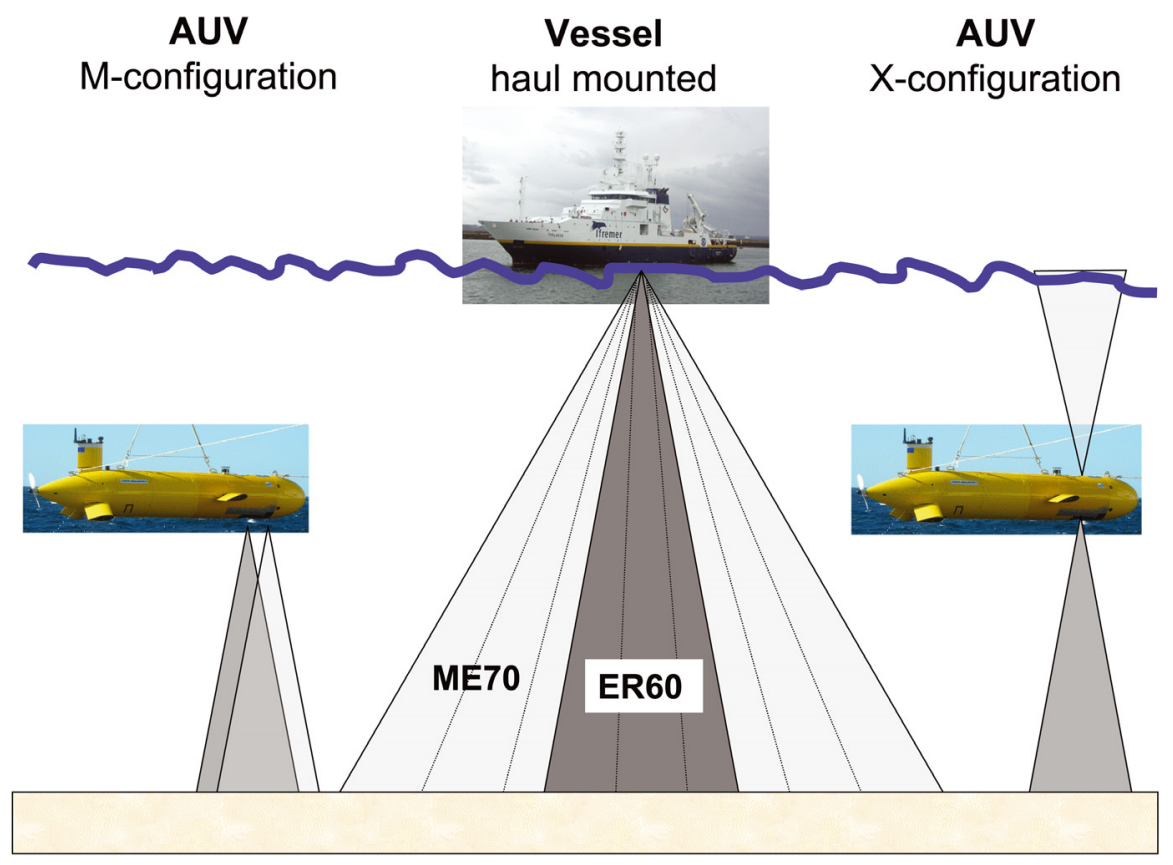

Fig. 1. Configurations and observation volume of AUV and vessel mounted acoustic transducers. ME70 multibeam echosounder; ER60 singlebeam echosounders. The AUV has two single-beam echosounders ( $70 \mathrm{kHz}$ and $200 \mathrm{kHz}$ ).

Table 1. Performance of Ifremer owned AUV manufactured by International Submarine Engineering Ltd. (ISE, Canada): $4.5 \mathrm{~m}$ long, $793 \mathrm{~kg}$.

\begin{tabular}{ll}
\hline Parameter & Performance \\
\hline max. depth & $3000 \mathrm{~m}$ \\
max. speed & $5 \mathrm{knots}$ (without current) \\
max. distance & $100 \mathrm{~km}$ \\
acoustic payload & 70 and $200 \mathrm{kHz}$ \\
navigation & fixed depth or altitude \\
\hline
\end{tabular}

(Fig. 1 shows the $\mathrm{M}$ and X configurations). Several AUV field trials were carried out, including an extensive study in the Bay of Biscay in September 2007 (Scalabrin et al. 2009). The latter study provided observations of pelagic fish in the surface blind zone and demersal fish close to the bottom. For example, in one comparison carried out during this study, the AUV was positioned at an average immersion of $50 \mathrm{~m}$ below the sea surface and the acoustic transducers were in X-configuration, i.e. one looking up and the other down (Fig. 1). Trawling showed that fish found near the surface were mainly anchovy. The average anchovy density estimated based on AUV and vessel data was 16630 and $1193 \mathrm{~kg}$ per square nautical mile respectively. The large difference is due to anchovy schools in the surface blind zone of the vessel with some contribution from other schools down to 30-m depth. However, the surface blind zone, alone, cannot explain this large difference, suggesting that fish avoidance of the vessel might also have played a role. These results from an area with high anchovy densities are preliminary and should be confirmed by future experiments. Given that spatial distributions have been found to be linked to environmental conditions (Castillo et al. 1996), the proportion of individuals found close to the sea surface can be expected to depend on oceanographic conditions and species behaviour and might vary according to different temporal and spatial scales. Fish biomass found in the bottom dead zone was also investigated during the survey in 2007 . The results indicate that for abundant species such as hake it might be possible to obtain biomass estimates using acoustics on an AUV platform (Scalabrin et al. 2009).

Several obstacles have to be overcome before the Ifremer AUVs become operational and can contribute to biomass indices for routine stock assessment. First, given the slow speed ( $<5$ knots without current), it is impractical to use them to survey large areas such as the entire Bay of Biscay. Adaptive sampling designs, such as AUV deployment only when high concentrations in surface layers are suspected, might help to optimise their contribution. Second, because of safety reasons and lack of legislation, the AUV currently needs to be escorted by a rather large support vessel able to intervene in case of technical problems. Third, given that transducer performance may be depth- or temperature-dependent (Demer and Renfree 2008), tank calibrations should be confirmed by in situ measurements. The Institute of Marine Research (IMR), Norway, has developed a tool for calibration of deepwater transducers at different depths. The output of the method provides a vertical profile of calibration results that can be used to compensate acoustic data according to the immersion depth profile of the AUV. The AUV transducers were specially designed for deepwater use; however, it appears that a variation of up to $2 \mathrm{~dB}$ could occur in the calibration results between the transducer at the surface and at $200 \mathrm{~m}$ depth (E. Ona, pers. comm.).

\subsection{Improving sampling coverage and resolution}

The step from vertical acoustic observations in two dimensions (depth and time or distance) to three, adding the 


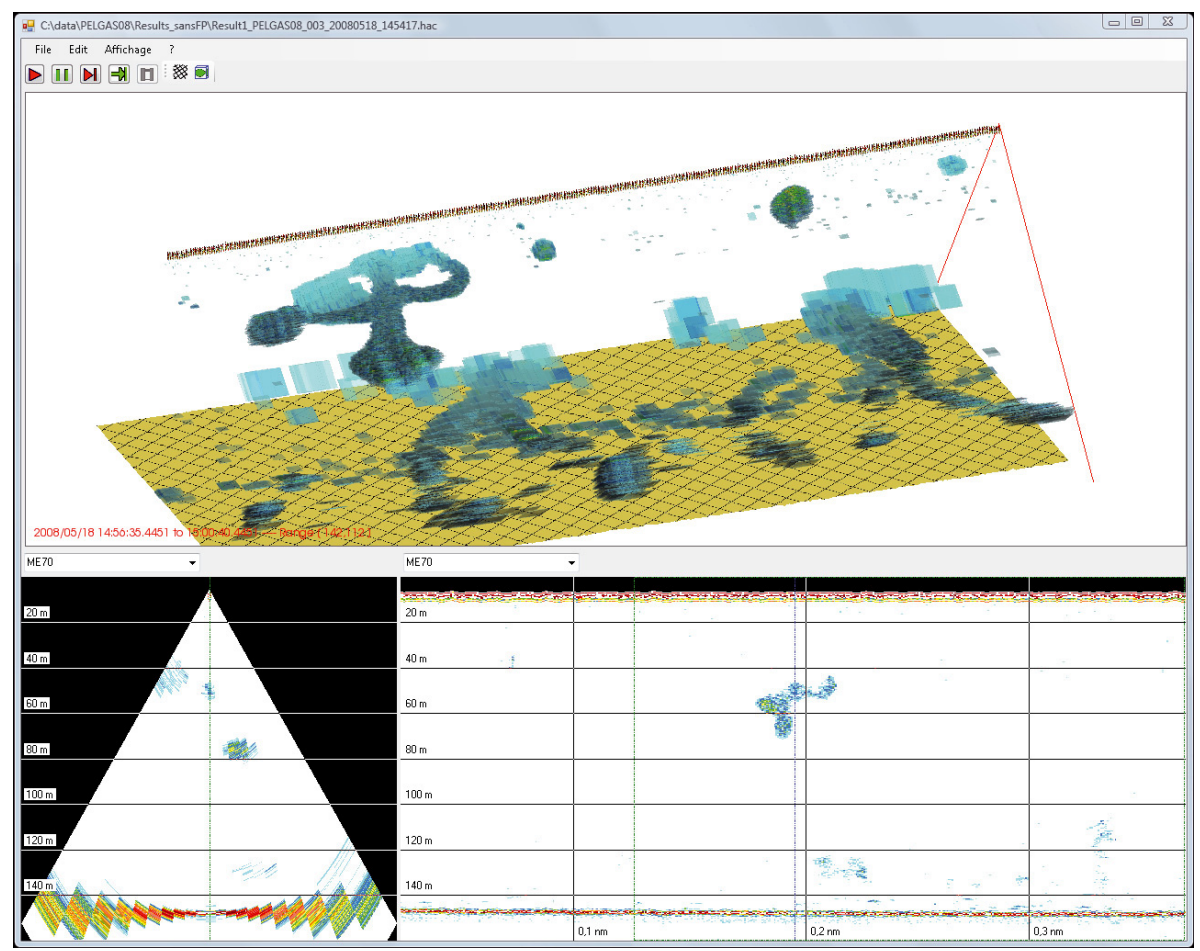

Fig. 2. Two- and three-dimensional images of a fish schools in the Bay of Biscay visualised using MOVIES 3D software. Top: 3D view with vessel advancing in North-eastern direction. Bottom left: $2 \mathrm{D}$ view across beams. Bottom right: traditional longitudinal view for beam indicated by vertical line in bottom left and vessel advancing to the right.

across-ship dimension, was made with the introduction of multibeam sonars (Gerlotto et al. 1999; Gerlotto and Paramo 2003). More recently, the multibeam echosounder ME70 has added quantitative 3D back-scattered energy measurements as it is fully calibrated, in contrast to many of the earlier multibeam sonars. Reduced side lobes allow observing diffuse aggregations in combination with dense schools or individuals close to the bottom. Due to its multiple beams, the 3D structure of fish schools can now be visualised and quantitatively characterized (i.e. energy wise) (Fig. 2). Increased spatial resolution is achieved with narrower beam widths (minimum $2.2^{\circ}$ ) compared to traditional echosounders $\left(7-10^{\circ}\right)$. Roll and pitch beam stabilization and reduced side-lobe levels, up to $-70 \mathrm{~dB}$ (two-way) instead of the $-25 \mathrm{~dB}$ commonly found in multibeam sonars, make this system unique for fishery research applications (Trenkel et al. 2008).

A procedure for in situ calibration of the ME70 across all beams and the entire frequency band $70-120 \mathrm{kHz}$ was developed in collaboration with Norwegian colleagues (Ona et al. 2009). Two sets of tungsten carbide spheres are available for the calibration: i) a small sphere ( $25 \mathrm{~mm}$ diameter) allowing to calibrate the system with target strengths from -43 to $-46 \mathrm{~dB}$ in the full frequency bandwidth, and ii) two large spheres (75 and $84 \mathrm{~mm}$ diameter) with high target strengths from -32 to $-34 \mathrm{~dB}$. These two large spheres were specifically designed to facilitate the calibration as they are sufficiently heavy to stabilize the calibration rig (the small sphere requires the use of an additional weight) and their high target strengths permit to unambiguously separate biological targets that might be in the observation volume. However, as the target strength spectrum for spheres of this size contains both sharp peaks and deep nulls within the band of interest (Foote 2006), the calibration of a complete beam configuration requires the use of both spheres to cover the frequency bandwidth.

Compared to single-beam multi-frequency ER60 echosounders, the ME70 collects data of similar quality in a larger volume, with a higher resolution and an additional dimension. In order to simultaneously control all echosounders (ME70 and ER60s) on board, the HERMES software was developed. This software controls the configuration and emission of all echosounders to avoid interference between them, stores all data in a single file using the HAC format (standard format to allow interchange of raw and edited hydroacoustics data, and independent of specific echosounders, software and computer platforms, ICES 2005) and manages data distribution on the network (Fig. 3, top part). The HERMES software also handles advanced configuration modes for the ME70, which has been designed as a customisable equipment in order to allow exploratory work for analysing TS variations as a function of beam angle and frequency. Expected performances of a given configuration in terms of side lobe levels and beam footprints are predicted by HERMES and shown in graphical form.

\section{Analysing and combining acoustic observations: MOVIES 3D}

With the addition of the multibeam echosounder ME70, the quantity of data to be treated, as well as the types of 
analyses that can be carried out, has increased substantially. The software SBI Viewer, which was developed in the AVITIS project (Hamitouche-Djabou et al. 1999), was the first tool for visualizing and deriving metrics on fish schools from Reson Seabat 6012 multibeam echosounder data. To meet the challenge of combining quantitative single-beam multi-frequency and multibeam data, a new modular software is currently being developed, called MOVIES 3D (Fig. 3). The modular aspect is important for exploratory research that at a later stage will lead to an operational tool for routine acoustic surveys. All modules can be interfaced via a third party software such as Matlab (The Mathworks, Inc., Natick, MA), which facilitates the exploratory process and speeds up progress. The current progress and content of MOVIES 3D is presented for the modules for visualization, bottom detection, data pre-processing by filtering, school detection and school descriptor calculation, and school classification (see below).

\subsection{Data visualization}

The visualization module of MOVIES 3D allows simultaneous representation of selected multibeam and single-beam echosounder data (Fig. 3, right-hand side). The selected data can be either all data, only overlapping data, i.e. data with the same observation volume (see Sect. 3.3), or data for selected targets such as schools. In contrast to existing software packages, the real geometric shape of the observation volume of each data sample is represented in three dimensions, including the increase in the observation volume with depth, the overlap between successive pings and the transversal position (Fig. 2). This allows the user to appreciate the volume sampled by each echosounder beam and to see at a glance the degree of overlap. On R/V Thalassa, the single-beam echosounders and the ME70 are installed in close proximity on the vessel hull, which means that they are observing overlapping but not identical scenes. In addition to the position on the hull, differences in beam opening contribute to the differences in observation volume of the different echosounders. Further, the ME70 is compensated for vessel roll and pitch, while single-beam echosounders are not. As a result of the visualization of the real observation volumes, taking also into account vessel heading, more realistic school images for interpretation of fish school morphology are available. Real-time access to this representation already helps qualitative analysis of species compositions.

\subsection{Improving bottom detection}

High fish densities close to the seabed, soft or sloping bottoms (or oblique beams) can lead to false detections by commonly used bottom detection algorithms relying on echoamplitude measurements alone, as reported by MacLennan et al. (2004). These authors demonstrated empirically that phase information provided by split-beam echosounders might allow to discriminate between the seabed and fish echoes. The phase information is already routinely used for steered beams in bathymetric applications (e.g. Lurton 2000, 2002).

All beams of the ME70 and the traditional single-beam echosounders can be operated in split-beam mode. Furthermore, due to the reduced side-lobe levels in the beam array pattern of the ME70, improved detection of fishes close to the bottom, and hence separation of the seabed from the fish, should be possible. To accurately locate the bottom in all beams, the use of both amplitude and phase information for bottom detection in near-normal and outer beams of the ME70 was investigated (Bourguignon et al. 2009). Bourguignon et al. developed a Bayesian particle filtering algorithm (Doucet 1998) which exploits the spatial contiguity between the measurements of subsequent pings for the same beam and potentially neighbouring ME70 beams for the same ping using the barycentre in echo amplitude around the maximum for beams with incidence angles below $15^{\circ}$ and the cancellation in the athwartship phase-difference signal for beam incidence angles above $15^{\circ}$. This bottom continuity particle filtering (BCPF) method was tested in shallow $(\sim 30 \mathrm{~m})$ and in for deeper sea bottoms, $(\sim 200 \mathrm{~m})$ using data sets collected in the English channel and Bay of Biscay respectively. In the shallow bottom data set, the BCPF was quite successful in locating the bottom despite the presence of dense herring schools close to the seabed. Similarly, for the deeper bottom data, the BCPF led to improved bottom localisation in all ME70 beams, compared to traditional amplitude thresholding alone. The current version of the BCPF, available in MOVIES 3D, works rather well for a flat or smoothly-sloping seabed. To improve the performance of the BCPF for all seabed types, the inclusion of information on the seabed slope in the algorithm will be explored in future work.

\subsection{Improving frequency response curves using filtered data}

For certain fish species, for example mackerel (Scomber scombrus), the reflected energy depends on the echosounder frequency, which means that the mackerel exhibits a distinct frequency response curve (Korneliussen and Ona 2003). For mackerel, the response is higher at higher frequencies (i.e. higher at $200 \mathrm{kHz}$ than at $18 \mathrm{kHz}$ ) due to the lack of swimbladder, which is the most reflecting body part in most fish species (Simmonds and MacLennan 2005). Many modern fisheries research vessels have several single-beam echosounders operating at different frequencies and mounted in close proximity on the vessel hull. However, direct comparison of data collected with different beams to obtain frequency response curves is not straightforward due to slight differences in the observation volume which can become preponderant in case of small structures (Korneliussen et al. 2008). Due to these problems, only imprecise empirical frequency response curves are currently available for many species.

Berger et al. (2009) developed a method (available in MOVIES 3D) for filtering fish schools observed by several beams. The filtering method makes use of the true school position provided by the roll and pitch stabilized ME70, the positions and orientations of the transducers and the dynamic position of the vessel. This allows the removal of echoes from the single-beam echosounders that were not simultaneously observed by all frequencies. The filtered data can then be used to study the in situ frequency response of fish schools with increased accuracy (2D/3D filtered data visualisation in Fig. 3), which is a first step towards species identification. 
Table 2. Input parameters for MOVIES 3D software for detecting 3D aggregations in acoustic backscatter of ME70.

\begin{tabular}{|c|c|c|}
\hline Parameter & $\begin{array}{l}\text { Suitable } \\
\text { value }\end{array}$ & Comment \\
\hline Energy threshold & $-60.0 \mathrm{~dB}$ & Threshold value for all beams \\
\hline $\begin{array}{l}\text { Maximum vertical } \\
\text { distance factor }\end{array}$ & 1.0 & $\begin{array}{l}\text { Floating number multiplied with } \\
\text { vertical resolution (capacity of the } \\
\text { system to resolve two targets in range, } \\
\text { i.e. pulse length } \times \text { sound speed } / 2 \text { ) } \\
\text { to be used as vertical integration } \\
\text { distance }\end{array}$ \\
\hline $\begin{array}{l}\text { Maximum athwart } \\
\text { ship distance }\end{array}$ & $0.2 \mathrm{~m}$ & $\begin{array}{l}\text { Maximum athwart ship distance } \\
\text { between two echoes in same school }\end{array}$ \\
\hline $\begin{array}{l}\text { Maximum along } \\
\text { ship distance }\end{array}$ & $2 \mathrm{~m}$ & $\begin{array}{l}\text { Maximum along ship distance } \\
\text { between two echoes (pings) in same } \\
\text { school in direction of vessel track }\end{array}$ \\
\hline Minimum height & $2 \mathrm{~m}$ & $\begin{array}{l}\text { Minimum height for the detected } \\
\text { aggregation }\end{array}$ \\
\hline Minimum width & $5 \mathrm{~m}$ & $\begin{array}{l}\text { Minimum width for the detected } \\
\text { aggregation }\end{array}$ \\
\hline Minimum length & $5 \mathrm{~m}$ & $\begin{array}{l}\text { Minimum length for the detected } \\
\text { aggregation }\end{array}$ \\
\hline
\end{tabular}

voxel: sampling unit, corresponds to echo of fixed width in a single ping in a given beam.

\subsection{Detecting and describing three dimensional structures}

Several software tools have been developed for extracting morphological and energetic descriptors of fish schools in 2D (Weill et al. 1993; Coetzee 2000) and from sonars in 3D (Lecornu et al. 1998; Gerlotto et al. 1999; Brehmer et al. 2007). Studying the three-dimensional structure of aggregations with the ME70 requires extending existing algorithms in terms of additional input parameters for school detection and parameters for describing the detected three-dimensional objects.

Input parameters similar to existing 2D and 3D algorithms are used for school detection in MOVIES 3D (Table 2). The only additional input parameter is a maximum distance in the transversal direction. In two dimensions, it has been found that two detection parameters, energy density threshold and minimum dimensions, are determining factors for the number and dimensions of extracted schools (Burgos and Horne 2007). These parameters can be expected to be also determining in three dimensions. In addition, the energy threshold value might have to be modulated with respect to beam angle and echosounder frequency; research is underway to investigate this question.

The sampling unit of detected schools is the voxel (similar to a pixel in 2D). The volume of a voxel increases with depth and depends on beam opening. The center of each voxel is spatially referenced by its geographic and depth position. All subsequent school morphology descriptors are derived from the positions of these basic voxels. For example, the average depth of a oxels' school can be calculated as the simple mean across all voxels depths in the school or as a weighted mean where the backscattered energy of each voxel is taken as weight.

Parameters for describing the three-dimensional structure of extracted schools have been defined based on school voxel positions and measurements of school slices (Table 3). Figure 4 illustrates the horizontal and vertical school slices used for determining maximum length, width and height. Note that for this approach a school is assumed to be a compact entity even if in reality this may not be the case. For example, maximum school length is measured between extreme voxels in the horizontal plane, which could mean across an empty space in the school. Compared to two-dimensional school images, the additional parameters that have become available are school width, school position with respect to the vessel track and school volume and surface, if the whole school was observed.

Initial results for anchovy schools observed at around $100 \mathrm{~m}$ depth some $20 \mathrm{~m}$ above the seabed with the ME70 (21 beams, $70-120 \mathrm{kHz}$ ) in the Southern Bay of Biscay (CLASS08 survey) in June 2008 indicated that maximum school width was slightly smaller $(80 \%)$ than maximum school length (Fig. 5a). This apparent asymmetry might, at least partially, be explained by the difference in resolution in the alongship (5 to $8 \mathrm{~m}$ ) and athwartship direction ( 5 to $20 \mathrm{~m}$ ) for beams with incidence angles $0^{\circ}$ to $40^{\circ}$ at a depth of about 100 metres. In addition, it could be the result of vessel avoidance reactions following the hypothesis proposed by Soria et al. (2003), according to which avoidance movements of fish within the school increase inter-individual distance parallel to the vessel path, thus making the school more elongated. School height was about ten times smaller than school length (Fig. 5b).

\subsection{Advancing species identification}

In biomass estimation by acoustics it is important to apportion the echoes between species or species groups, e.g. clupeids. Most operational systems rely on experts' interpretation of echograms and the use of species composition of trawl hauls. The automation of the interpretation of the echograms has also been investigated (Haralambous and Georgakarakos 1996; Scalabrin et al. 1996). Most techniques rely on the extraction of fish schools and on their characterization using various features, including school morphology or shape and acoustic energy. More recently, multifrequency signatures have also been considered for Atlantic herring and Norway pout (Jech and Michaels 2006; Fässler et al. 2007), Atlantic mackerel (Gorska et al. 2005) and deep-water species (Kloser et al. 2002). Besides school characterization, the choice of the classification scheme is also critical. Most proposed classification schemes (Haralambous and Georgakarakos 1996; Scalabrin et al. 1996; Hammond and Swartzman 2001) used "supervised training" of the classification models based on a dataset with known species. Such schemes are however not suitable for multispecies environments, such as the Bay of Biscay, where trawl catches are composed of a mixture of different species. It is then impossible to create a representative dataset of schools where each school is associated with a single species, and consequently a supervised training strategy cannot be applied. To overcome this problem, a novel approach for school classification and species proportion estimation was developed by Fablet et al. (2009). These authors first segmented the acoustic records along the survey track into successive 


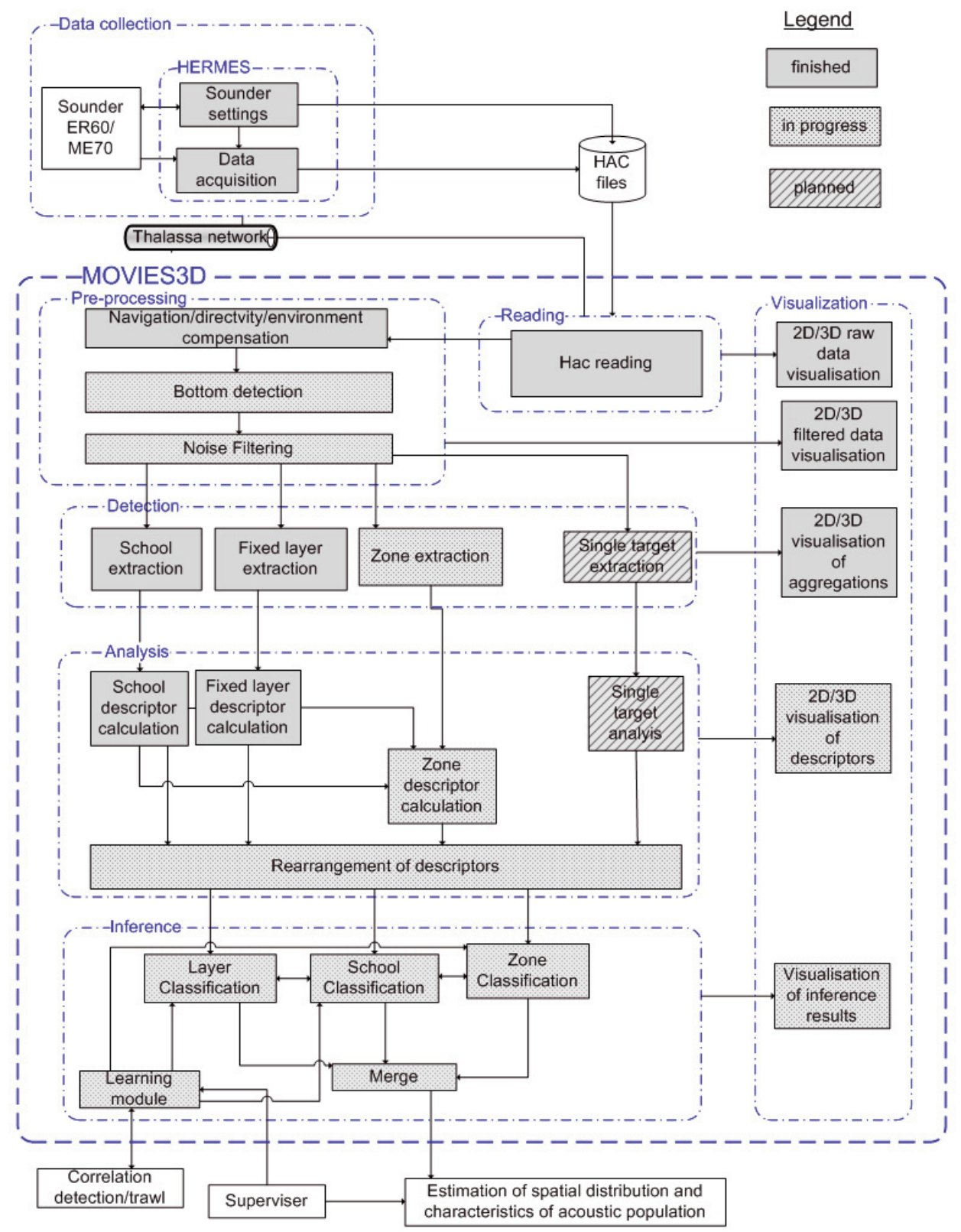

Fig. 3. Schematic view of MOVIES 3D software structure for joint analysis of acoustic data from multibeam echosounder (ME70) and singlebeam echosounders (five frequencies).

three-nautical-mile echograms and then carried out school detection and characterisation in these echograms. School classification models are trained using the data collected at trawled sites, i.e. echograms with known relative species proportions. The models can then be used both to assign a species to a given school and to estimate relative species proportions in any echogram. In a second approach, echograms were analysed on a global level following Petitgas et al. (2003). Each echogram instead of school was characterized by a set of descriptors. The relative species proportions were then inferred from the similarities between an echogram and the echograms at trawled sites, without any actual classification of individual schools.

\section{Spatial distribution of small pelagic fish in the Bay of Biscay}

The spatial distribution of small pelagic fish is shaped by their gregarious behaviour. They usually display up to four levels of spatial aggregation during the day, suggesting a fractal structure (Fréon et al. 2005). Petitgas (2001) identified schools, clusters of schools and assemblages of clusters of small pelagic fish in the Bay of Biscay, based on acoustic data. He hypothesized that clusters of schools could be controlled by the dynamic behaviour of schools at the small scale, whereas assemblages of clusters could be influenced by environmental 
Table 3. Descriptors of three-dimensional fish schools as implemented in MOVIES 3D software.

\begin{tabular}{|c|c|}
\hline Parameter & Description \\
\hline Depth: minimum, maximum and mean & $\begin{array}{l}\text { Smallest and largest distance from sea surface to } \\
\text { top of school; mean of depth of voxels in school. }\end{array}$ \\
\hline Altitude: minimum and maximum & $\begin{array}{l}\text { Smallest and largest distance from sea floor to } \\
\text { bottom of school. }\end{array}$ \\
\hline Height: maximum & $\begin{array}{l}\text { Maximum height (value and horizontal distance } \\
\text { from vessel track, Figs. } 4 \mathrm{~b}, \mathrm{c} \text { ). }\end{array}$ \\
\hline $\begin{array}{l}\text { Geographic position: geometric } \\
\text { and weighted }\end{array}$ & $\begin{array}{l}\text { Mean latitude and longitude of school voxel centres } \\
\text { or weighted mean using voxel energy. }\end{array}$ \\
\hline Width: maximum & $\begin{array}{l}\text { Maximum width (value and depth of occurrence, } \\
\text { Fig. 4a). }\end{array}$ \\
\hline Length: maximum & $\begin{array}{l}\text { Maximum length (value and depth of occurrence, } \\
\text { Fig. 4a). }\end{array}$ \\
\hline Relative position: start and angle & $\begin{array}{l}\text { Horizontal distance from vessel track of start of } \\
\text { school (Fig. } 4 c) \text { and angle of position wrt to track } \\
(\beta \text { in Fig. } 4 \text { d). }\end{array}$ \\
\hline $\begin{array}{l}\text { Volume: voxel volume and school } \\
\text { angle }\end{array}$ & $\begin{array}{l}\text { Volume of school as defined by its voxels and } \\
\text { opening angle for cone including school ( } \alpha \text { in } \\
\text { Fig. 4d). }\end{array}$ \\
\hline Surface & Surface of school as defined by its voxels \\
\hline Energy: total and weighted & $\begin{array}{l}\text { Total energy as sum of energy of voxels or } \\
\text { weighted by voxel volume }\end{array}$ \\
\hline
\end{tabular}

voxel: sampling unit, corresponds to echo of fixed width in a single ping in a given beam (see Fig. 6).

a)

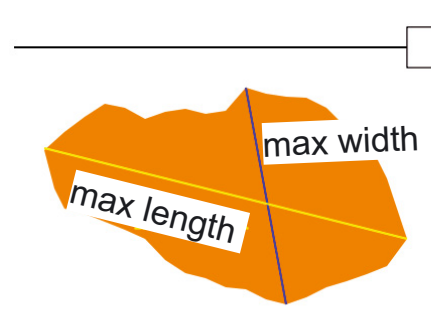

b)

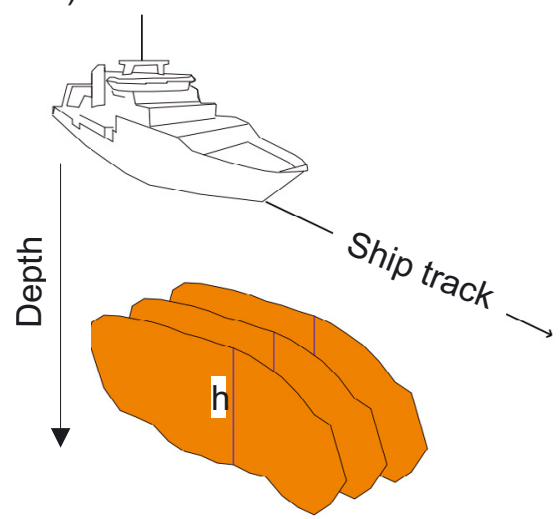

c)

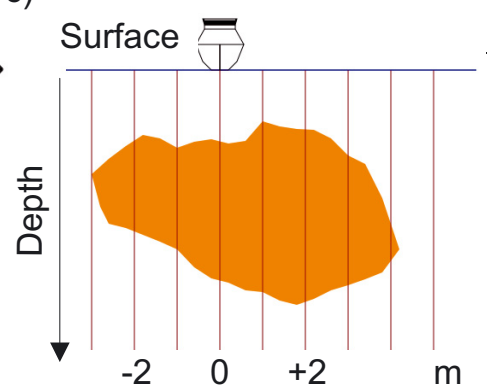

d)

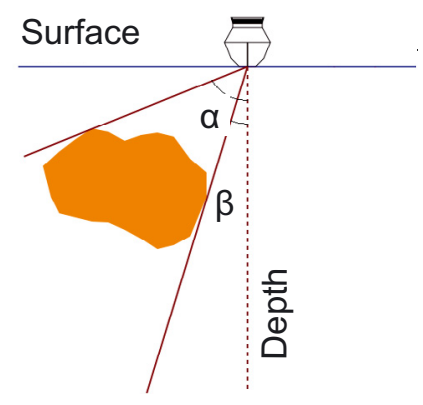

Fig. 4. Descriptors for three dimensional structure of fish schools as implemented in MOVIES 3D. a) maximum length and width by depth layer; b) maximum height $h$ and length $l$ by vertical slice (parallel to ship track); c) same as b) but frontal view; d) school position with respect to vessel. 
a)

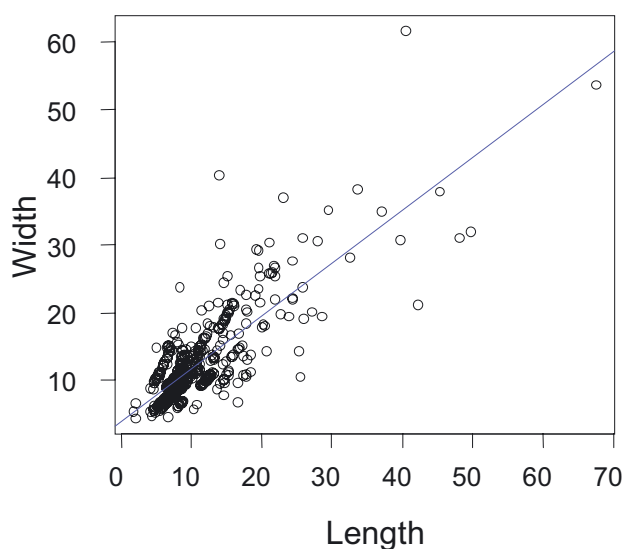

b)

width $=0.1{ }^{*}$ length

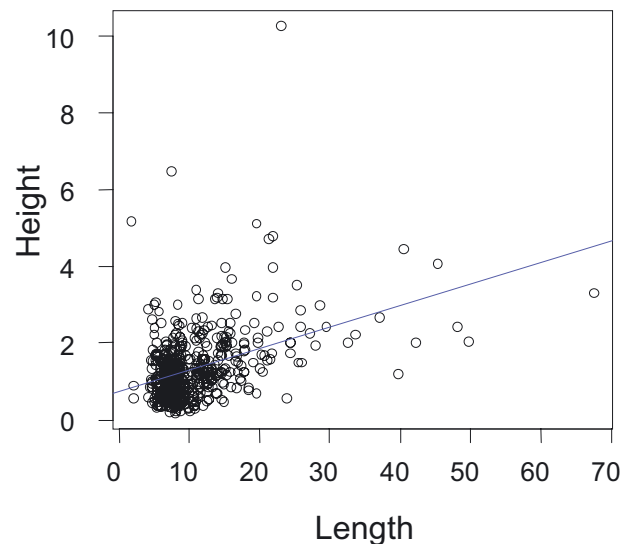

Fig. 5. Relationship between maximum school length and maximum school width (a) and school length and maximum school height (b) for 552 schools in the Bay of Biscay which are most likely anchovy.

factors structured at the regional scale. The spatial distribution of anchovy at the mesoscale (dozen of $\mathrm{km}$ ) displayed significant correlation with plankton communities commonly found in river plumes and in the southern coastal areas of the Bay of Biscay (Petitgas et al. 2006). Moreover, small pelagic species generally undergo regional scale migrations, thought to be evolutionary adaptations to seasonal changes in food availability or search for spawning habitats favourable for offspring survival (Fréon et al. 2005). On a smaller scale, their vertical distribution changes through life history stages as well as on a daily basis (Zwolinski et al. 2007; Orlowski 2005), and their internal organisation structure varies from well-structured schools to more diffuse layers, often in conjunction with a diel activity cycle of feeding and resting (Bertrand et al. 2006; Zwolinski et al. 2007).

\subsection{Vertical distributions}

The vertical structure of the pelagic fish assemblage in spring in the Bay of Biscay has been described extensively based on single-beam echosounder data. Horse mackerel are generally found close to the sea floor, while anchovy are detached from the sea floor and migrate to the surface at night. Sardine always appear as dense schools in the whole water column. When present, sprat and sardine seem to be mingled with anchovy (Massé et al. 1996; Massé and Gerlotto 2003). No patterns in the inter-annual variation of the minimum distance of schools from the seabed have been evidenced, but large intra-annual variations were found (Villalobos 2008). On average, anchovy schools were most consistently found close to the seabed, and also had the smallest coefficients of variation (CV) of school distance from the seabed (40-80\%) compared to horse-mackerel and sardine, whose CVs were larger (horsemackerel 40-140\%; sardine 70-410\%). Villalobos (2008) suggests that the relative stability of anchovy school distances might be due to the relatively low population abundance during the study period.

In spring 2008, during the spawning period of anchovy, a scientific survey (CLASS08) was carried out in the Bay of
Biscay with R/V Thalassa for collecting multifrequency and multibeam acoustic data. The areas sampled encompassed the shelf break (down to $250 \mathrm{~m}$ ), a coastal area called Landes, south of the Gironde river estuary (30-110 m) and a shallow area in southern Brittany $(30-50 \mathrm{~m})$. The dominant species varied between areas. Pelagic fishing hauls confirmed the presence of horse-mackerel in all areas except southern Brittany, where mainly sardine was caught. In the coastal Landes area, horse-mackerel was found mixed with large quantities of anchovy. The three-dimensional information provided by the ME70 allowed for the visualisation of the vertical layering of different schools, with horse mackerel in a layer close to the bottom in daytime, either on its own near the shelf break (Fig. 6a) or with anchovy above it in the Landes area (Fig. 6b). Anchovy generally formed ribbon-like, complex aggregative structures (Fig. 6c). Based on 2D information, it was previously thought that anchovy formed many small schools. The $3 \mathrm{D}$ observations now indicate that the small schools might be ribbon-like structures cut into pieces by single-beam 2D observations, but of course also by the limits of the observation volume of the ME70. Further, the ME70 allowed for the observation of interesting behavioural features, such as the spreading of small pelagic schools at sunset (Fig. 6d). Changes in school morphology and vertical position in the Bay of Biscay have already been noted based on traditional two-dimensional acoustic observations (Massé and Gerlotto 2003). The third dimension adds to this understanding as it offers the possibility to describe the vertical overlap of aggregations in more detail.

\subsection{Geographic distributions}

The day-time geographic distribution of anchovy in the Bay of Biscay in May was found to be associated with turbid, nutrient-rich coastal waters in the Southern part, while the distribution of sardine during the same period was unrelated to water mass characteristics (Petitgas et al. 2006). As a consequence, the day-time geographic distribution of sardines is more variable between years but also more widespread (Massé 1996; Massé and Gerlotto 2003). 
a)

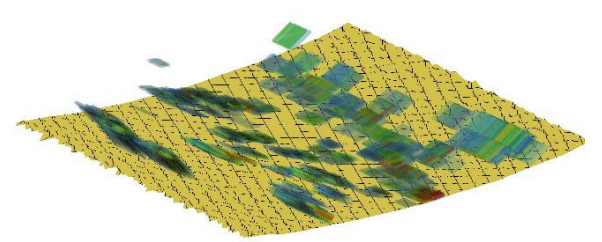

c)

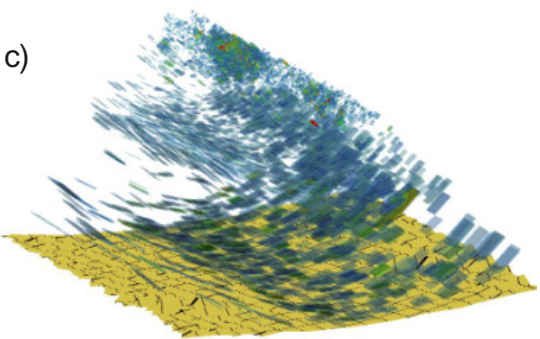

b)
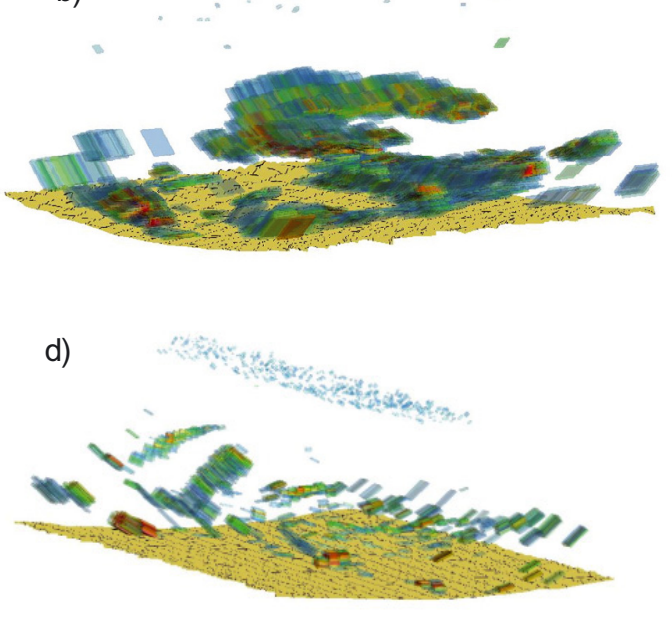

Fig. 6. Three dimensional school structure and relationship between species in the Bay of Biscay. a) horse-mackerel early in the morning close to sea bottom $(177 \mathrm{~m})$; b) horse-mackerel close to bottom and anchovy detached at noon (106 $\mathrm{m})$; c) probably anchovy close to surface just after dusk (104 m); d) dispersed small pelagic fish in the late afternoon (109 m).

The large scale distribution of pelagic species (anchovy, sardine, sprat, mackerel, horse mackerel and blue whiting) in the Bay of Biscay was analysed using single-beam PELGAS survey data (collected in May every year) for the years 20002006. The findings confirm those by Petitgas et al. (2006). In all seven years, anchovy was found close to the coast in two areas in the Southern part of the bay (Fig. 7a). Sprat was also distributed close to the coast, but in a smaller, concentrated area in front of the Gironde estuary (Fig. 7b). The location of large sardines $(>18.5 \mathrm{~cm})$ was rather widespread throughout the bay and variable between years (Fig. 7c), while small sardines $(<18.5 \mathrm{~cm})$ were more common in the southern part, overlapping with anchovy (Fig. 8d). A spatial size gradient was also found for anchovy (Fig. 8a) and mackerel (Fig. 8b), with larger individuals being distributed more offshore. The opposite pattern was found for blue whiting, for which larger individuals were closer to the coast in shallow water (Fig. 8c).

In a more comprehensive study using ten years of singlebeam acoustic survey data during the period 1990 to 2003 in the same area, the possible linkages between the spatial distribution of fish in terms of geographic position, schooling patterns and environmental conditions were analysed (Villalobos 2008). The analysis resulted in the definition of six groups of "acoustic populations" defined by school characteristics, spatial distribution and assemblage structure (Gerlotto 1993). The results indicate that the appearance of these acoustic populations is more closely linked with hydrographic characteristics (sea surface salinity, bottom temperature, depth of mixed layer and potential energy deficit) as identified by Planque et al. (2004) than with species identity.

\section{Perspectives}

In this paper, recent methodological progress made by Ifremer in fisheries acoustics is presented even though many

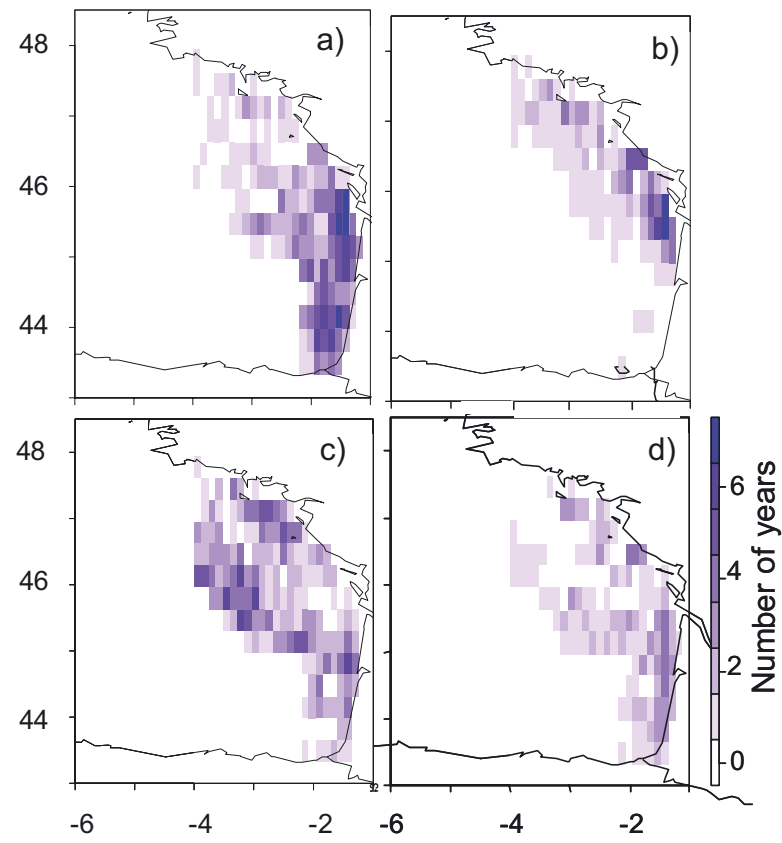

Fig. 7. Number of years where species were observed in a given location in spring in the Bay of Biscay during PELGAS acoustic surveys (2000-2006). a) anchovy, b) sprat, c) big sardine (>18.5 cm), d) small sardine $(<18.5 \mathrm{~cm})$.

developments are still ongoing. The biggest step was the development of the multibeam echosounder ME70, which added a spatial dimension to acoustic investigations. The tools needed for analysing the additional quantity of data that can now be collected are only starting to be developed. There is a need to move from visualising the data to making quantitative analyses. However, the 3D images alone have already changed our view of the pelagic fish community in the Bay of Biscay. While previous 2D images indicated the presence of many 


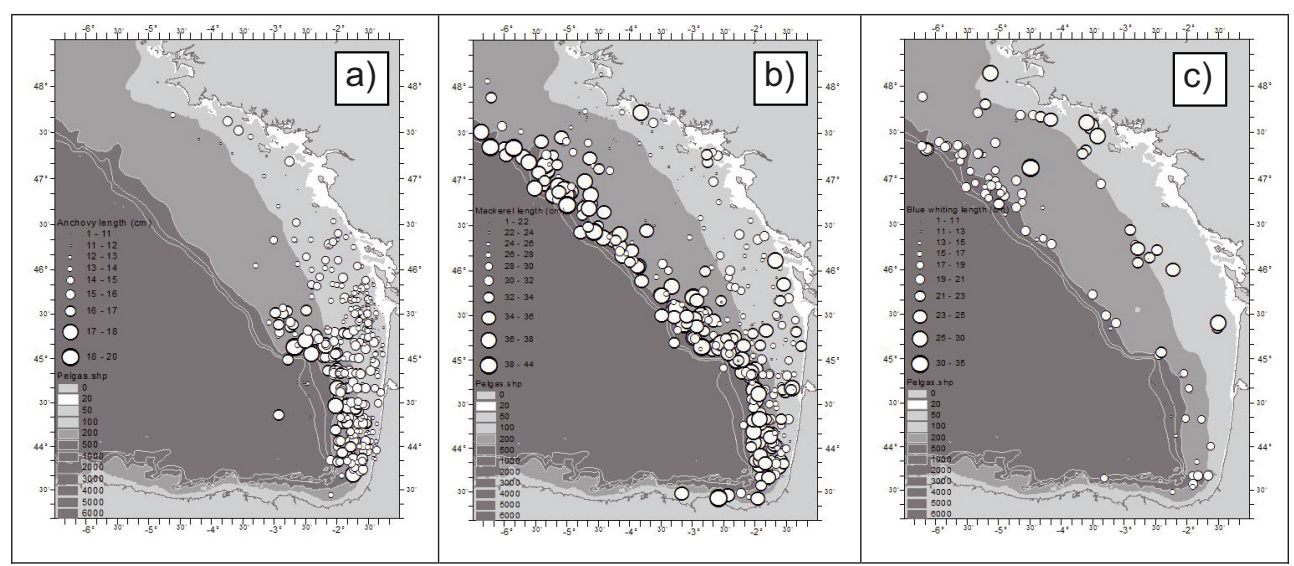

Fig. 8. Average size distribution of anchovy (a), mackerel (b), blue whiting (c), in spring in the Bay of Biscay (1983-2006, with gaps) as determined from pelagic trawl hauls. Circle diameter is proportional to average body size.

small schools, we now realise that these are often connected to form more diffuse structures. As for quantitative analyses, developing 3D school descriptors (Sect. 3.4) is only the first step. Further descriptors for non-compact schools and ribbons are a logical next step, for example using global geostatistical descriptors or landscape indices (Burgos and Horne 2008), accompanied by the development of appropriate segmentation approaches to extract homogeneous structures (e.g., compact 3D schools vs. diffuse aggregative structures). For the latter issue, simple thresholding with the same value for all beams seems no longer satisfactory, and other approaches need to be tested. This work is underway. The discriminate power of these new descriptors for species identification need to be evaluated by pursuing the approaches summarised in Section 3.5. In addition, the sensitivity of school descriptors to the position of the school in the fan (depth, athwartship position) and echosounder frequency requires more in-depth investigations. Preliminary results from dense herring (Clupeus harengus) schools in the English Channel indicate that, at least for herring, the athwartship position $\left( \pm 40^{\circ}\right.$ observation angle) explains little of the observed variability in backscattered energy, which confirms the simulation results presented by Cutter and Demer (2007). Lastly, methods for joint use of singlebeam multi-frequency and multibeam data for quantitative fish biomass estimation have to be developed. Two options can be envisaged, which differ in the degree of integration of the different data sources: i) biomass estimation based on data from the $38 \mathrm{kHz}$ ER60 (traditional method) and use of other frequencies $(70 \mathrm{KHz}, 120 \mathrm{kHz}$ and $200 \mathrm{kHz})$ and ME70 data for visual scrutiny to aid species identification and ii) biomass estimation using only ME70 data and five frequencies from ER60s for species identification in automatic or semi-automatic classification methods of species or species-groups. Option i) is already operational in 2009.

Making use of the information on the additional dimension, many old but also new ecological and stock-related questions can now be reinvestigated (Koslow 2009). For example, the functioning of pelagic schools could be elucidated by studying the relationship between school structure and school dynamics, for example by tracking schools in 3D (Trygonis et al. 2009) and relating the two to environmental conditions on different spatial scales (Bertrand et al. 2008). Routinely quantifying school reactions to the approaching vessel might allow the correction of biomass estimates for behaviour-induced estimation bias, at least partially. Variations in trawl catchability are related to the spatial organisation of fishes, with diffuse layers being more difficult to catch and hence potentially leading to negative bias in biomass estimates for those species (Villalobos 2008). The 3D information provided by the ME70 could provide an index for the presence of diffuse structures and possibly lead to a modified sampling strategy for the location of identification hauls. Implementation of an ecosystem approach to fisheries management will require a wealth of information, not only on the biomass of exploited species but also on the relationship between predators and preys, on species relations in schools, on relations between schooling patterns and environmental conditions, etc. Acoustics in general and the ME70 in particular are going to be an essential tool for ecosystem studies (Koslow 2009). In conclusion, much progress has been made, but even more is still ahead.

Acknowledgements. We thank our colleges for onboard assistance during the scientific surveys Allegro, Pelgas08 and Class08. Part of the reported work was financially supported by the projet ITISACSYS (Pôle Mer Bretagne). Hector Villalobos was supported by a fellowship of the Comisión de Operación y Fomento de Actividades Académicas (COFAAS).

\section{References}

Axenrot T., Didrikas T., Danielsson C., Hansson S., 2004, Diel patterns in pelagic fish behaviour and distribution observed from a stationary, bottom-mounted, and upward-facing transducer. ICES J. Mar. Sci. 61, 1100-1104.

Berger L., Poncelet C., Trenkel V.M., 2009, A method for reducing uncertainty in estimates of fish-school frequency response using data from multifrequency and multibeam echosounders. ICES J. Mar. Sci. 66, 1155-1161.

Bertrand A., Barbieri M.A., Gerlotto, F., Leiva F., Córova J., 2006, Determinism and plasticity of fish schooling behaviour as 
exemplified by the South Pacific jack mackerel Trachurus murphyi. Mar. Ecol. Prog. Ser. 311, 145-156.

Bertrand A., Gerlotto F., Bertrand S., Gutiérrez M., Alza L., Chipollini A., Díaz E., Espinoza P., Ledesma J., Quesquén R., Peraltilla S., Chavez F., 2008, Schooling behaviour and environmental forcing in relation to achoveta distribution: An analysis across multiple spatial scales. Prog. Oceanogr. 79, 264-277.

Bourguignon S., Berger L., Scalabrin C., Fablet R., Mazauric V., 2009, Methodological developments for improved bottom detection with the ME70 multibeam echosounder. ICES J. Mar. Sci. 66, 1015-1022.

Brehmer P., Georgakarakos S., Josse E., Trygonis V., Dalen J., 2007, Adaptation of fisheries sonar for monitoring schools of large pelagic fish: dependence of schooling behaviour on fish finding efficiency. Aquat. Living Resour. 20, 377-384.

Burgos J.M., Horne J.K., 2007, Sensitivity analysis and parameter selection for detecting aggregations in acoustic data. ICES J. Mar. Sci. 64, 160-168.

Burgos J.M., Horne J.K., 2008, Characterization and classification of acoustically detected fish spatial distributions. ICES J. Mar. Sci. $65,1235-1247$.

Castillo J., Barbieri M.A., Gonzalez A., 1996, Relationships between sea surface temperature, salinity and pelagic fish distribution off northern Chile. ICES J. Mar. Sci. 53, 139-146.

Coetzee J., 2000, Use of a shoal analysis and patch estimation system (SHAPES) to characterise sardine schools. Aquat. Living Resour. $13,1-10$.

Cutter Jr. G.R., Demer D.A., 2007, Accounting for scattering directivity and fish behaviour in multibeam-echsounder surveys. ICES J. Mar. Sci. 64, 1664-1674.

Dalen J., Nedreaas K., Pedersen R., 2003, A comparative acousticabundance estimation of pelagic redfish (Sebastes mentella) from hull-mounted and deep-towed acoustic systems. ICES J. Mar. Sci. 60, 472-479.

De Robertis A., Hjellvik V., Williamson N.J., Wilson C.D., 2008, Silent ships do not always encounter more fish: comparison of acoustic backscatter recorded by a noise-reduced and a conventional research vessel. ICES J. Mar. Sci. 65, 623-635.

Demer D.A., Renfree J.S., 2008, Variations in echosoundertransducer performance with water temperature. ICES J. Mar. Sci. 65, 1021-1035.

Diner N., Le Men R., 1983, Evaluation acoustique des stocks de poisson pélagiques dans la partie sud du golfe de Gascogne en avrilmai 83. ICES CM 1983/H: 44.

Diner N., 1999, Correction of school geometry and density: an approach based on acoustic image simulation. ICES Coop. Res. Rep. 238, 27-51.

Diner N., 2001, Correction on school geometry and density: approach based on acoustic image simulation. Aquat. Living Resour. 14, 211-222.

Doray M., Josse E., Gervain P., Reynal L., Chantrel J., 2007, Joint use of echosounding, fishing and video techniques to assess the structure of fish aggregations around moored Fish Aggregating Devices in Martinique (Lesser Antilles). Aquat. Living Resour. 20, 357-366.

Doucet A., 1998, On sequential simulation-based methods for Bayesian filtering. Signal Processing Department, University, Cambridge.

Fabi G., Sala A., 2002, An assessment of biomass and diel activity of fish at an artificial reef (Adriatic Sea) using a stationary hydroacoustic technique. ICES J. Mar. Sci. 59, 411-420.

Fablet R., Lefort R., Karoui I., Berger L., Massé J., Scalabrin C., Boucher J.M., 2009, Classifying fish schools and estimating their species proportions in fishery-acoustic surveys. ICES J. Mar. Sci. 66, 1136-1142.

Fässler S.M.M., Santos R., García-Nuñez N., Fernandes P.G., 2007, Multifrequency backscattering properties of Atlantic herring (Clupea harengus) and Norway pout (Trisopterus esmarkii). Can. J. Fish. Aquat. Sci. 64, 362-374.

Fernandes P.G., Brierley A.S., Simmonds E.J., Millards N.W., McPhail S.D., Armstrong F., Stevenson P., Squires M., 2000, Fish do not avoid survey vessels. Nature 404, 35-36.

Fernandes P.G., Stevenson P., Brierley A.S., Armstrong F., Simmonds E.J., 2003, Autonomous underwater vehicles: future platforms for fisheries acoustics. ICES J. Mar. Sci. 60, 684-691.

Foote K.G., 2006, Optimizing two targets for calibrating a broadband multibeam sonar. Oceans 2006 Conference, Boston MA, Vol. 14, pp. 1499-1502.

Fréon P., Cury P., Shannon L., Roy C., 2005, Sustainable exploitation of small pelagic fish stocks challenged by environmental and ecosystem changes: a review. Bull. Mar. Sci. 76, 385-462.

Gerlotto F., 1993, Identification and spatial stratification of tropical fish concentrations using acoustic populations. Aquat. Living Resour. 6, 243-254.

Gerlotto F., Soria M., Fréon P., 1999, From two dimensions to three: the use of multibeam sonar for a new approach in fisheries acoustics. Can. J. Fish. Aquat. Sci. 56, 6-12.

Gerlotto F., Paramo J., 2003, The three-dimensional morphology and internal structure of clupeid schools as observed using vertical scanning multibeam sonar. Aquat. Living Resour. 16, 113-122.

Gerlotto F., Castillo J., Saavedra A., Barbieri M.A., Espejo M., Cotel P., 2004, Three-dimensional structure and avoidance behaviour of anchovy and common sardine schools in central southern Chile. ICES J. Mar. Sci. 61, 1120-1126.

Gorska N., Ona E., Korneliussen R., 2005, Acoustic backscattering by Atlantic mackerel as being representative of fish that lack a swimbladder, backscattering by individual fish. ICES J. Mar. Sci. 62, 984-995.

Hamitouche-Djabou C., Togni S., Lecornu L., 1999, SBI Viewer: 3D fish schools and sea bottom analysis and visualisation software. User's Guide. AVITIS Contract FAIR CT 96-1717, Development release 3-10 June, 1999 Dpt ITI, ENST-Bretagne, Brest.

Hammond T.R., Swartzman G.L., 2001, A general procedure for estimating the composition of fish school clusters using standard acoustic survey data. ICES J. Mar. Sci. 58, 1115-1132.

Handegard N.O., Tjøstheim, D., 2005, When fish meet a travelling vessel: examining the behaviour of gadoids using a free-floating buoy and acoustic split-beam tracking. Can. J. Fish. Aquat. Sci. $62,2409-2422$.

Haralambous J., Georgakarakos S., 1996, Artificial neural networks as a tool for species identification of fish schools. ICES J. Mar. Sci. 53, 173-180.

ICES, 2005, Description of the ICES HAC standard data exchange format, Version 1.60. ICES Coop. Res. Rep. 278.

Jech J.M., Michaels W.L., 2006, A multifrequency method to classify and evaluate fisheries acoustics data. Can. J. Fish. Aquat. Sci. 63, 2225-2235.

Kloser R.J., 1996, Improved precision of acoustic surveys of benthopelagic fish by means of deep-towed transducer. ICES J. Mar. Sci. 53, 407-413.

Kloser R.J., Ryan T., Sakov A., Williams A., Koslow J.A., 2002, Species identification in deep water using multiple acoustic frequencies. Can. J. Fish. Aquat. Sci. 59, 1065-1077.

Korneliussen R., Ona E., 2003, Synthetic echograms generated from relative frequency response. ICES J. Mar. Sci. 60, 636-640. 
Korneliussen R.J., Diner N., Ona E., Berger L., Fernandes P.G., 2008, Proposals for the collection of multifrequency acoustic data. ICES J. Mar. Sci. 65, 982-994.

Koslow, J.A. 2009, The role of acoustics in ecosystem-based fishery management. ICES J. Mar. Sci. 66, 966-973.

Lecornu L., Burdin V., Scalabrin C., Hamitouche C., 1998, Fish school analysis from multibeam sonar image processing. Oceans 98 Conference, Nice, pp. 587-591.

Lurton X., 2000, Swath bathymetry using phase difference: Theoretical analysis of acoustical measurement precision. IEEE J. Ocean. Engine. 25, 351-363.

Lurton, X., 2002, An introduction to underwater acoustics: Principles and applications. Springer Verlag.

MacLennan D.N., Copland P.J., Armstrong E., Simmonds E.J., 2004, Experiments on the discrimination of fish and seabed echoes. ICES J. Mar. Sci. 61, 201-210.

Massé J., Rouxel C., 1991, Improvement in acoustic assessments by discrimination of pelagic shoals with INES/MOVIES system. ICES Annual Science Conference, CM 1991/B:26.

Massé J., 1996, Acoustic observations in the Bay of Biscay: schooling, vertical distribution, species assemblages and behaviour. Sci. Mar. 60 (Suppl. 2), 227-234.

Massé J., Koutsikopoulos C., Patty W., 1996, The structure and spatial distribution of pelagic fish schools in multispecies clusters: an acoustic study. ICES J. Mar. Sci. 53, 155-160.

Massé J., Gerlotto F., 2003, Introducing nature in fisheries research: the use of underwater acoustics for an ecosystem approach of fish population. Aquat. Living Resour. 16, 107-112.

Moreno G., Josse E., Brehmer P., Nøttestadd L., 2007, Echotrace classification and spatial distribution of pelagic fish aggregations around drifting fish aggregating devices (DFAD). Aquat. Living Resour. 20, 343-356.

Ona E., Mitson R.B., 1996, Acoustic sampling and signal processing near the seabed: the deadzone revisited. ICES J. Mar. Sci. 53, 677-690.

Ona E., Godø O.R., Handegard N.O., Hjellvik V., Patel R., Pedersen G., 2007, Silent research vessels are not quiet. J. Acoust. Soc. Am. 121, 145-150.

Ona E., Mazauric V., Andersen L.N., 2009, Calibration methods for two scientific multibeam systems. ICES J. Mar. Sci. 66, 13261334.

Opderbecke J., Laframboise J.-M., 2007, AUVs for oceanographic science at IFREMER, project progress and operational feedback. Oceans 2007 Conference, Vancouver, Vol. 1-5, pp. 356-360.

Orlowski A., 2005, Experimental verification of the acoustic characteristics of the clupeoid diel cycle in the Baltic. ICES J. Mar. Sci. $62,1180-1190$

Patel R., Handegard N.O., Godø O.R., 2004, Behaviour of herring (Clupea harengus L.) towards an approaching autonomous underwater vehicle. ICES J. Mar. Sci. 61, 1044-1049.

Petitgas P., Reid D., Carrera P., Iglesias M., Georgakarakos S., Liorzou B., Massé, J., 2001, On the relation between schools, clusters of schools, and abundance in pelagic fish stocks. ICES J. Mar. Sci. 58, 1150-2001.

Petitgas P., Massé J., Beillois P., Lebarbier E., Le Cann, A., 2003, Sampling variance of species identification in fisheries-acoustic surveys based on automated procedures associating acoustic images and trawl hauls. ICES J. Mar. Sci. 60, 437-445.

Petitgas P., Massé J., Bourriau P., Bellois P., Bergeron J.-P., Delmas D., Herbland A., Koueta N., Froidefond M., Santos, M., 2006, Hydro-plankton characteristics and their relationship with sardine and anchovy distributions on the French shelf of the Bay of Biscay. Sci. Mar. 70S1, 161-172.

Planque B., Lazure P., Jégou A.-M., 2004, Detecting hydrological landscapes over the Bay of Biscay continental shelf in spring. Climate Res. 28, 41-52.

Rigaud V., 2007, Innovation and operation with robotized underwater systems. J. Field Robotics 24, 449-459.

Scalabrin C., Massé J., 1993, Acoustic detection of the spatial and temporal distribution of fish shoals in the Bay of Biscay. Aquat. Living Resour. 6, 269-283.

Scalabrin C., Diner N., Weill A., Hillion A., Mouchot M.C., 1996, Narrowband acoustic identification of monospecific fish schools. ICES J. Mar. Sci. 53, 181-188.

Scalabrin C., Diner N., Veron G., Choqueuse D., Sanchez F., 2005, Autonomous bottom moored acoustic observatory for fisheries resources monitoring. Oceans 2005 Conference, Brest, Vol. 1-2.

Scalabrin C., Marfia C., Boucher J., 2009, How much fish is hidden in surface and bottom acoustic blind zones? ICES J. Mar. Sci. 66, 1355-1363.

Simmonds E.J., MacLennan D.N., 2005, Fisheries acoustics. Theory and practice. 2nd edition. Blackwell, Oxford.

Soria M., Bahri T., Gerlotto F., 2003, Effect of external factors (environment and survey vessel) on fish school characteristics observed by echosounder and multibeam sonar in the Mediterranean Sea. Aquat. Living Resour. 16, 145-157.

Totland A., Johansen G.O., Godø O.R., Ona E., Torkelsen T., 2009, Quantifying and reducing the surface blind zone and the seabed dead zone using new technology. ICES. Mar. Sci. 66, 1370-1376.

Trenkel V.M., Mazauric V., Berger L., 2008, The new multibeam fisheries echosounder ME70: description and expected contribution to fisheries research. ICES J. Mar. Sci. 65, 645-655.

Trevorrow M.V., 2005, The use of moored inverted echo sounders for monitoring meso-zooplankton and fish near the ocean surface. Can. J. Fish. Aquat. Sci. 62, 1004-1018.

Trygonis V., Georgakarakos S., Simmonds E.J., 2009, An operational system for automatic school identification on multi-beam sonar echoes. ICES J. Mar. Sci. 66, 935-949.

Villalobos H., 2008, Évolution de l'écosystème pélagique du golfe de Gascogne pendant la période 1990-2003. Conséquences sur la capturabilité des espèces. PhD, Université de Bretagne Occidentale.

Weill A., Scalabrin C., Diner N., 1993, MOVIES-B: an acoustic detection description software. Application to shoal species' classification. Aquat. Living Resour. 6, 255-267.

Zwolinski J., Morais A., Marques V., Stratoudakis Y., Fernandes P.G., 2007, Diel variation in the vertical distribution and schooling behaviour of sardine (Sardina pilchardus) off Portugal. ICES J. Mar. Sci. 64, 963-972. 